\title{
MUNICIPIO, INNOVACIÓN Y DESARROLLO EN LATINOAMÉRICA
}

\author{
Luis Rodríguez Castillo \\ lurodri@unam.mx \\ Proimmse-IIA \\ Universidad Nacional Autónoma de México
}

Innovación y desarrollo son conceptos que desde los años noventa del siglo pasado tienden a aparecer irremediablemente vinculados al gobierno local. Esto se debe a que, a la par de los procesos de descentralización impulsados por los Estados-nación, se promovió una visión en la que se prescribía que la municipalidad necesitaba innovarse para cumplir a cabalidad con funciones relacionadas a fomentar el desarrollo y el bienestar de la población local.

En las posturas normativas, «innovación» se consideró un concepto útil para identificar los elementos que impulsaban las transformaciones organizacionales e institucionales. Fundamentado en un lenguaje técnico y neutral, el término se convirtió, por extensión, en uno de los «tropos» maestros para explicar el cambio social en las últimas décadas. No obstante, actualmente se reconoce que el potencial analítico de esta noción yace en permitirnos estudiar las formas en las que se está reorientando el diseño de la acción pública municipal, los nuevos instrumentos de gestión e interacción entre gobierno y sociedad, y la reconfiguración de los actores que intervienen en proyectos a favor del desarrollo local (ver Arellano et al. 2000 y Cabrero et al. 1995).

La tríada que da nombre a este número de Pueblos y fronteras, digital, en sus diferentes combinaciones, ha tenido gran impacto especialmente en dos campos. Por un lado, aparecen innumerables transformaciones en las agendas globales, en las que se presenta con mayor insistencia lo local como la dimensión adecuada para la acción (como la Agenda 21, los Objetivos para el Desarrollo del Milenio, etc.) y, por el otro, se han transformado las prácticas de diferentes actores colectivos bajo nuevos lineamientos institucionales que 
insisten en que las políticas locales deben fomentar el desarrollo del capital social a través de la participación ciudadana.

En ese sentido, abre este número un ensayo teórico de Emanuel Rodríguez, quien hace una revisión crítica sobre el uso del concepto «capital social» en el marco de los debates del desarrollo. Postula que es necesario incorporar al análisis las relaciones asimétricas de poder, así como las disputas sociales. Para ello, recurre a la noción de campo social de Bourdieu y al instrumental metodológico del procesualismo de la llamada Escuela de Manchester en la antropología social.

Por su parte, Rodolfo Calderón Umaña critica el abordaje unidimensional y empobrecido del problema de la seguridad pública en Centroamérica y República Dominicana, que magnifica el aspecto represivo como solución. Argumenta que es necesario vincular la seguridad pública al desarrollo y a los derechos humanos desde el gobierno local, situando el papel de la municipalidad en el ámbito de la prevención y el fomento de la convivencia pacífica.

Posteriormente, Emmanuel Nájera de León se pregunta si una mayor presencia de miembros de los pueblos indígenas en gobiernos locales se traduce en innovaciones de las agendas políticas municipales. En el municipio de San Cristóbal de Las Casas dicha identidad genérica se representa como un «recurso» que ha sido instrumentalizado en el espacio público. En su conclusión, el autor afirma que la mayor presencia indígena no se ha traducido en innovaciones institucionales ni en la generación de una agenda indígena.

Dos colaboraciones presentan experiencias trasformadoras de municipalidades argentinas desde la perspectiva que ofrecen los proyectos de intervención social dirigidos desde la Universidad pública. Por un lado, Alejandro López Accotto, Carlos R. Martínez, Irene Grinberg y Cristian Adaro argumentan que el presupuesto participativo es a la vez una técnica para la innovación en la gestión pública y un instrumento para impulsar la 
participación ciudadana. Ello evidencia la necesidad de contar con recursos diversos por parte de un grupo complejo de actores, entre ellos, instituciones académicas como la Universidad Nacional de General Sarmiento. Por otro lado, Pablo Mendes Calado presenta un proyecto de la Universidad Nacional de Tres de Febrero para impulsar políticas culturales locales como un recurso para el desarrollo y la construcción de vínculos sociales. Observa positivamente que los funcionarios locales son partícipes de ideas como el respeto por la diversidad o la democratización del acceso a los servicios culturales. Sin embargo, un aspecto problemático es que el diálogo entre los funcionarios y los destinatarios de las políticas y servicios es escaso.

Mauricio Pineda Pertier analiza la labor realizada por el Archivo Etnográfico Audiovisual de la Universidad de Chile en la municipalidad de San Pedro de Atacama. Si bien el gobierno local es poco visible en el estudio, el autor concluye que el proyecto ha puesto al servicio de la municipalidad una herramienta útil para promover y valorar su patrimonio, así como para facilitar su explotación como recurso de desarrollo.

Regresando a estudios realizados en México, Ismael Couto Benítez, Alberto Hernández y Cecilia Sarabia presentan las innovaciones del municipio de Ciudad Juárez en materia de recolección de basura a través de una alianza con la iniciativa privada. Concluyen que el caso muestra nuevos retos para la administración de los servicios públicos a partir de prácticas de negociación, calidad en el servicio, rendición de cuentas y control gubernamental.

A continuación, Manuel Ignacio Martínez revisa el Proyecto Desarrollo Social Integrado y Sostenible, implementado en la región selva de Chiapas a partir de un modelo de análisis de gestión de proyectos de cooperación internacional al desarrollo basado en el campo de las políticas públicas. En su propuesta incorpora lo sugerido por Rodríguez en su artículo: un análisis del espacio de la política. Por su parte, Nancy Sierra, Alejandro Tonatiuh Romero y Lilia Zizumbo estudian los cambios derivados de la construcción en Valle de Bravo de una 
de las seis presas que forma parte del sistema hidroeléctrico Miguel Alemán en el sur del estado de México. Exponen cómo se trasformó la organización socioterritorial del municipio pero que ni éste ni sus pobladores tuvieron mayor injerencia en el proyecto ni obtuvieron beneficios.

Joaquín Quiroz Carranza y Citlalli Cantú exploran los impactos del Programa nacional de estufas ahorradoras de leña en Yucatán y Quintana Roo. Exponen cómo se está imponiendo un modelo que no cumple con las expectativas de los usuarios, ya que no se les acompaña ni en la adopción ni se le da seguimiento al funcionamiento de la tecnología. Asimismo, no existen mecanismos de monitoreo ni de evaluación del programa.

Cierran este número dos reseñas; una al libro coordinado por Antonio Higuera Bonfil, Creer y aprender. Retratos culturales de estudiantes universitarios elaborada por Miguel Lisbona. Y no podía faltar en este número dedicado al ámbito local de gobierno, la relatoría elaborada por Rodolfo García del Castillo del Primer foro de debate sobre la reforma política municipal organizado en mayo de 2011 por la red de Investigadores en Gobiernos Locales Mexicanos (Iglom).

En suma, los artículos que integran el presente número de la Revista Pueblos y fronteras, digital abordan las aristas de la relación entre gobierno local, innovación y sus resultados para impulsar el desarrollo en diversos espacios territoriales de América Latina: cinco de ellos se centran en las regiones sureste, norte y centro de México, uno presenta un análisis sobre la región Centroamericana y la República Dominicana, y tres más abordan casos de municipalidades en Argentina y Chile.

Indiscutiblemente, tanto el origen de la innovación como sus consecuencias son disparejas. En algunos casos, la transformación emerge de las respuestas de los gobiernos locales a las presiones de una sociedad civil que demanda mayor eficiencia en la acción gubernamental sobre áreas que atiende «tradicionalmente» ese orden de gobierno, como los servicios 
públicos. En otros, se trata de políticas municipales cuyo principal motor de cambio yace en la atención a nuevas áreas de trabajo, como las políticas culturales.

Otro factor de cambio proviene de macroproyectos de desarrollo regional respaldados por asistencia técnica internacional, quienes en sus lineamientos institucionales reivindican al gobierno local y a la participación ciudadana como ejes torales del progreso. Sin embargo, a pesar de contar en sus normativas con una perspectiva de planeación y desarrollo «territorial» que implicaría considerar al ámbito local de gobierno y a la ciudadanía como agentes primordiales del proceso de desarrollo, los dejan fuera debido a sus esquemas de operación, la magnitud de la obra de infraestructura programada, sus fuentes de financiamiento o las propias tendencias de centralización presentes en el espacio de la política pública. Eso explica por qué en muchos casos dichos proyectos terminan por dejar al nivel local de gobierno y a la participación ciudadana como mera figura decorativa.

Los análisis presentados difícilmente nos permiten concluir que la innovación conduzca indefectiblemente al «desarrollo». Éste es un concepto problemático, pues alude tanto a un ideal, como a un símbolo, a posibilidades de «intervención» e ingeniería sociales, o a un instrumento de poder. No obstante, sí es posible observar que los discursos y las prácticas del desarrollo y la innovación, hoy por hoy, se concentran en el aspecto participativo de la ciudadanía local y en su articulación con otros agentes policéntricos que generan nuevas formas de organización y reestructuran la manera en la que el gobierno local asume sus funciones. Éste es el motivo por el cual se ha considerado al municipio como uno de los protagonistas de la transición política y del fomento a las normas y valores que garantizan una vida democrática (ver Cabrero 2003 y Rodríguez 2009) ya que, según Peters (2007), tal tendencia implica una disminución de las decisiones jerárquicas en la toma de las decisiones públicas, aspecto que los artículos que integran este número destacan como un horizonte utópico. 


\section{BIBLIOGRAFÍA}

Arellano, David, Enrique Caballero y Arturo del Castillo (coordinadores), 2000, Reformando al gobierno. Una visión organizacional del cambio gubernamental, Centro de Investigación y Docencia Económicas, Miguel Ángel Porrúa, Colección Las Ciencias Sociales, Segunda Década, México.

Cabrero Mendoza, Enrique (coordinador), 2003, Políticas públicas municipales. Una agenda en construcción, Centro de Investigación y Docencia Económicas, Premio gobierno y gestión local, Miguel Ángel Porrúa, Colección Las Ciencias Sociales, Segunda Década, México.

Cabrero Mendoza, Enrique, Rodolfo García del Castillo y Martha Gutiérrez Mendoza, 1995, La nueva gestión municipal en México. Análisis de experiencias innovadoras de gobiernos locales, Centro de Investigación y Docencia Económicas, Miguel Ángel Porrúa, Colección Las Ciencias Sociales, México.

Rodríguez Wallenius, Carlos, 2009, Luchas municipalistas en México. Acciones ciudadanas por la democracia y el desarrollo local, Juan Pablos, Universidad Autónoma Metropolitana Unidad Xochimilco, Colección Teoría y Análisis, México.

Peters, B. Guy, 2007, «Measurement of Governance», en Encyclopedia of Governance, editado por Mark Bevir, Sage, California, London y New Delhi, pp. 364-381. 